RESEARCH PAPER P-605

\title{
THE POLITICAL VIABILITY OF THE US BASE SYSTEM IN ASIA AFTER A VIETNAM SETTLEMENT,
}

Angus M. Fraser

April 1970

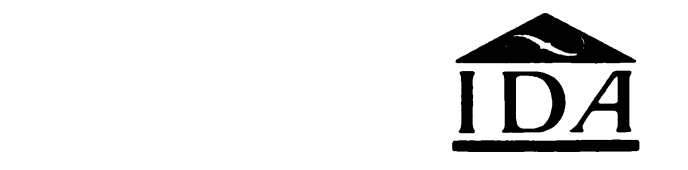

INSTITUTE FOR DEFENSE ANALYSES

INTERNATIONAL AND SOCIAL STUDIES DIVISION

400 Army-Navy Drive, Arlington, Virginia 22202

IDA Independent Research Program

$$
\text { NS }
$$

